\title{
The effectiveness of interventions to involve men living with HIV positive pregnant women in low-income countries: a systematic review of the literature
}

\author{
Isotta Triulzi ${ }^{1 *}$ D, Ilaria Palla ${ }^{1}$, Fausto Ciccacci ${ }^{2,3}$, Stefano Orlando ${ }^{2}$, Leonardo Palombi ${ }^{2}$ and Giuseppe Turchetti ${ }^{1}$
}

\begin{abstract}
Background: Male involvement (MI) along the continuum of HIV healthcare services has been promoted as a critical intervention in low-income countries and represents one of the reasons for dropout and low retention of women along the cascade of care. The present review aims to identify interventions adopted to improve Ml across Antenatal Clinics (ANCs).

Methods: For this systematic review, we searched electronic databases, including Scopus, PubMed, Web of Science (from 2008 to 2018) in English language. We included all interventions explicitly aimed at involving partners in pregnant women's HIV continuum of care and we excluded studies performed in developed countries, not involving pregnant women. We followed the PRISMA checklist.

Results: We identified a total of 1694 records and excluded 1651 after duplicates were removed and abstract eligibility assessments were performed. Forty-three full-text articles were screened, but only 12 studies were included. Recurrent intermediate outcomes were antenatal partner attendance rate and male HIV testing. We subdivided articles according to the type of intervention: single intervention (7) and multiple interventions (5). Among single interventions, two studies evaluated the use of an invitation letter sent via women to encourage male attendance to the ANC. Four Randomized Controlled Trials (RCTs) compared the invitation card (standard of care, SC) to word of mouth, information letter, home visit and invitation card plus partner tracing. The partner attendance rate was lower in SC than in the intervention arm in three RCTs: information letter (14.2\% vs $16.2 \%)$, home-visit (39\% vs $87 \%$ ) and invitation card plus partner tracing (52\% vs $74 \%$ ). Home visit strategies seemed the most effective. One study evaluated words of encouragement adopted to trigger women to invite their partners. Among multiple interventions, the most effective strategies in terms of male attendance included health promotion through education and healthcare worker development. These interventions were more likely to be effective in promoting Ml than single interventions.
\end{abstract}

Conclusions: From the review emerges the importance of male involvement in HIV cascade for pregnant women in countries with a significant HIV incidence and the need to define more precise indicators for measuring MI.

Keywords: Male involvement, Attendance to prenatal care, Pregnant women, Antenatal clinic, Prevention of mother-to-child transmission, HIV, Low income countries, Health prevention

\footnotetext{
* Correspondence: isotta.triulzi@santannnapisa.it

${ }^{1}$ Institute of Management, Scuola Superiore Sant'Anna, Piazza Martiri della

Libertà, 33, 56127 Pisa, Italy

Full list of author information is available at the end of the article
}

(c) The Author(s). 2019 Open Access This article is distributed under the terms of the Creative Commons Attribution 4.0 International License (http://creativecommons.org/licenses/by/4.0/), which permits unrestricted use, distribution, and

reproduction in any medium, provided you give appropriate credit to the original author(s) and the source, provide a link to the Creative Commons license, and indicate if changes were made. The Creative Commons Public Domain Dedication waiver (http://creativecommons.org/publicdomain/zero/1.0/) applies to the data made available in this article, unless otherwise stated. 


\section{Background}

The term male involvement refers to "engaging men to participate in health services together with their partners, especially in Antenatal Clinical settings" [1]. Male involvement (MI) represents a critical issue in maternal and child healthcare services in developing countries [2] and is associated with improved maternal adherence and retention [3-5] and reduction of infant HIV infection [6-8].

The lack of male partner involvement along the continuum of HIV healthcare services represents one of the main reasons for treatment refusal, delayed enrolment, dropout and low retention of pregnant and breastfeeding women $[2,9,10]$.

Although MI is a not well-defined concept and there is no a conventional way to evaluate and measure it, it is possible to identify gaps that affect men's health-seeking behaviours and discourage from looking after themselves and their partners. The significant causes of non-involvement is due to cultural, societal and gender factors, socio-economic factors, health service barriers and policy gaps [5, 11, 12].

According to UNAIDS, despite social and economic advantages, men use to seek out health care less than women, both for HIV testing and for Antiretroviral Therapy (ART) therapy. In fact, across Sub-Saharan Africa (SSA), the knowledge of HIV status is lower in men and boys than in women and girls living with HIV [13].

The need to involve males has been increasingly recognized since 1990, but only in 2012 the World Health Organization set partner involvement as one of the priority interventions to improve PMTCT (Prevention of Mother-to-Child Transmission) outcomes [2]. Unfortunately, efforts to promote sexual health and health prevention campaigns are aimed exclusively at women [14-16]. In the scientific literature, many studies highlight the importance of including men in care to improve health outcomes of female partners, but very few interventions have been proposed and implemented on a large scale [17-19].

The present study aims to review and evaluate the effectiveness of the interventions adopted to improve male involvement in PMTCT as an intermediate outcome to improve effectiveness of HIV/AIDS treatment and prevention programs targeting women. Although the final outcome to which the interventions aim is women's health, in this review we have considered as given the relationship between MI and women's health and we have limited the analysis to the effectiveness of interventions in promoting MI.

\section{Methods}

\section{Identification of the studies}

We decided to perform a systematic review to evaluate the effectiveness of the existing interventions [20] using PubMed, Scopus and Web of Science. PubMed is an ideal tool that offers a quick free search with various keywords and it is readily update compared to Scopus and Web of Science. Given that PubMed is mainly focused on medicine and biomedical sciences, we searched though Scopus and Web of Science that cover social sciences and humanities and larger number of journals [21]. The electronic search strategy for PubMed was: ((HIV[Title/Abstract] OR AIDS[Title/Abstract]) AND (Male[Title/Abstract] OR men[Title/Abstract] OR man[Title/Abstract] OR husband[Title/Abstract] OR couple[Title/Abstract] OR partner[Title/Abstract])) AND (PMTCT[Title/Abstract] OR MTCT[Title/Abstract] OR mother-to-child transmission[Title/Abstract] OR vertical transmission[Title/Abstract] OR pPTCT[Title/Abstract] OR pregnant[Title/Abstract]) AND (“2008/10/01”[PDat]: “2018/09/28"[PDat] AND "humans"[MeSH Terms] AND English[lang]).

Furthermore, reference lists and key journals have been hand-searched. The search referred to the period October 2008-October 2018 adopting the search strategy indicated in the table (Additional File 1: Table S1).

We followed the fundamental principles of systematic review according to PRISMA 2009 (Preferred Reporting Items for Systematic Reviews and Meta-Analyses) checklist (Additional File 1: Table S2).

\section{Inclusion criteria}

- Study Population: HIV+ and HIV- pregnant women and their male partners

- Interventions: all types of studies testing interventions and strategies to involve male partners in antenatal settings. We included all interventions explicitly aimed at involving partners in pregnant women's HIV continuum of care.

- Outcomes: all the outcomes that measured male involvement

- Countries: low income countries around the world

- Language: English

\section{Exclusion criteria}

We excluded studies not written in the English language and all papers published before 2008. Conference proceedings, case reports, systematic reviews, reviews, letters, and commentaries also were ruled out. We excluded studies where the component of MI was marginal.

\section{Study selection}

We followed a three-step processes for the evaluation of the studies. First, one researcher screened 
titles and abstracts of all identified studies which have been double-checked by a second reviewer. Secondly, two reviewers applied independently inclusion criteria on the full texts of the obtained articles. A third researcher resolved discordance between reviewers. Finally, data were extrapolated by two reviewers and then cross-checked. Finally, extrapolated.

\section{Data items}

The data extracted included the following items: Authorship, year of study, and journal; Country where the study was conducted; Objectives; Study design; Study duration; Sample size; Characteristics of participants; Results; Conclusion.

The meta-analysis was not feasible due to the heterogeneity of the studies (design, measured outcomes),

so we completed a narrative synthesis for each intervention.

We considered separately the included studies with multiple integrated components and studies specifically designed to assess the effect of a standalone male involvement intervention.

The outcomes measures showed different dimensions depending on the design of the study: the rate of male attendance, Odd Ratio (OR), Risk Relative (RR) and Risk Difference (RD) (Fig. 1).

\section{Results}

\section{Study selection}

We identified a total of 1694 papers from three databases. After removing the duplicates, we screened 1210 titles from which 252 abstracts met the inclusion criteria. The reasons for the exclusion were: the studies did not assess an intervention, they were qualitative studies, the study population was from high-income countries, they were focused on special population groups, and they were based on clinical trial not yet concluded.

Therefore 43 full-text articles were initially included in the review. Of these 31 were subsequently excluded for the following reasons: they were not focused on male involvement or related interventions; they were research protocols; they were qualitative papers; the aim of the study was not related to male involvement, attendance, accompanying and testing. 12 full-text papers were finally included in the review (Fig. 1).

\section{Study characteristics}

All studies aimed to assess interventions to increase involvement of males in healthcare services offered in Antenatal Clinic (ANC) and the population included pregnant women who were both HIV positive and negative accessing healthcare services.

The included studies have been published from 2011 to 2018, and all the papers were related to SSA: Kenya (4), Malawi (3), Mozambique (1), Uganda (1), Nigeria (1), Tanzania (1) and South Africa (1). HIV/ AIDS-related journals published most of the studies as Journal of Acquired Immune Deficiency Syndromes, AIDS and Behaviour, Journal of the International AIDS Society, Lancet HIV and Antiretroviral Therapy.

All studies focused on the male involvement issue, but there was no conventional way to evaluate and measure it [9]. In some studies, a male partner is involved if he escorts his partner to the antenatal clinic at least once $[22,23]$ or during a follow-up period of 4 weeks [24]. Nearly half of these studies did not explicitly define the concept. The adopted outcomes varied among the studies, but the recurrent outcomes were the antenatal attendance rate of the male partner (Proportion of pregnant women who attended ANC with their partners) and the male partner's HIV test (Proportion of men who accepted routine antenatal HIV testing).

We included six experimental studies and six observational studies. These clinical studies were classified using an algorithm proposed by Grimes DA [25]. Among the experimental studies, six were randomized controlled trials. Among the observational studies, two showed a pre-post invention design [22, 26], two papers adopted a prospective cohort design $[6,27]$ and one a three different period interventions [28].

We described the papers (Table 1) based on the type of intervention: single intervention (7) and multiple integrated component (5) interventions.

\section{Single intervention}

We considered researches that evaluated only one strategy to improve the participation of men as a single intervention study. Seven studies met this criteria, four of these were randomized controlled trials. Six interventions adopted the use of an invitation letter and one intervention introduced word of encouragement to involve partners.

\section{Interventions based on invitation letter}

Six studies adopted a strategy based on invitation cardin Malawi (2), Kenya (2), Tanzania (1) and Uganda (1). The interventions varied from 3 months to 4 years and were provided through antenatal care visits. Four out of six studies were randomized controlled trials. 


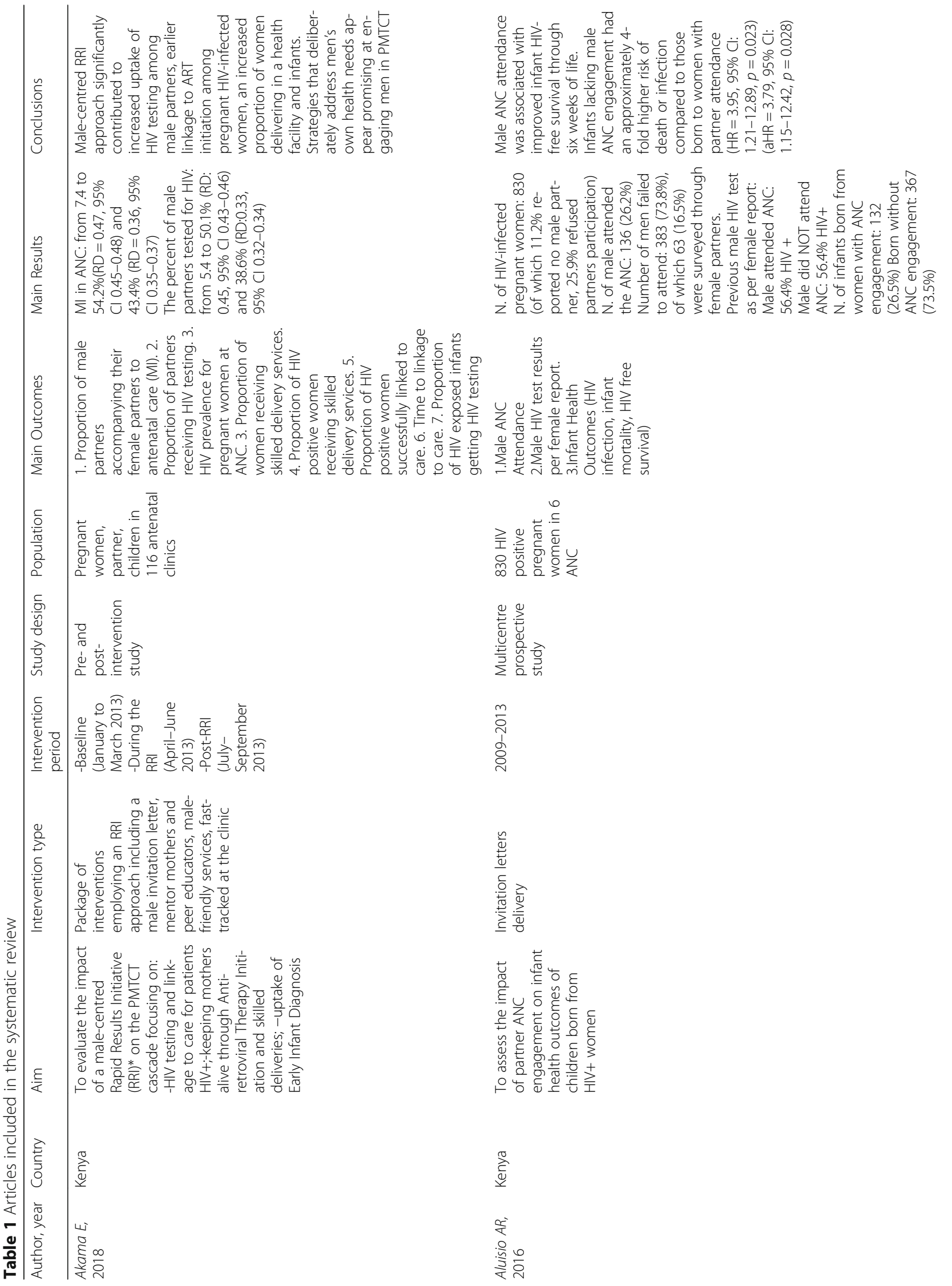




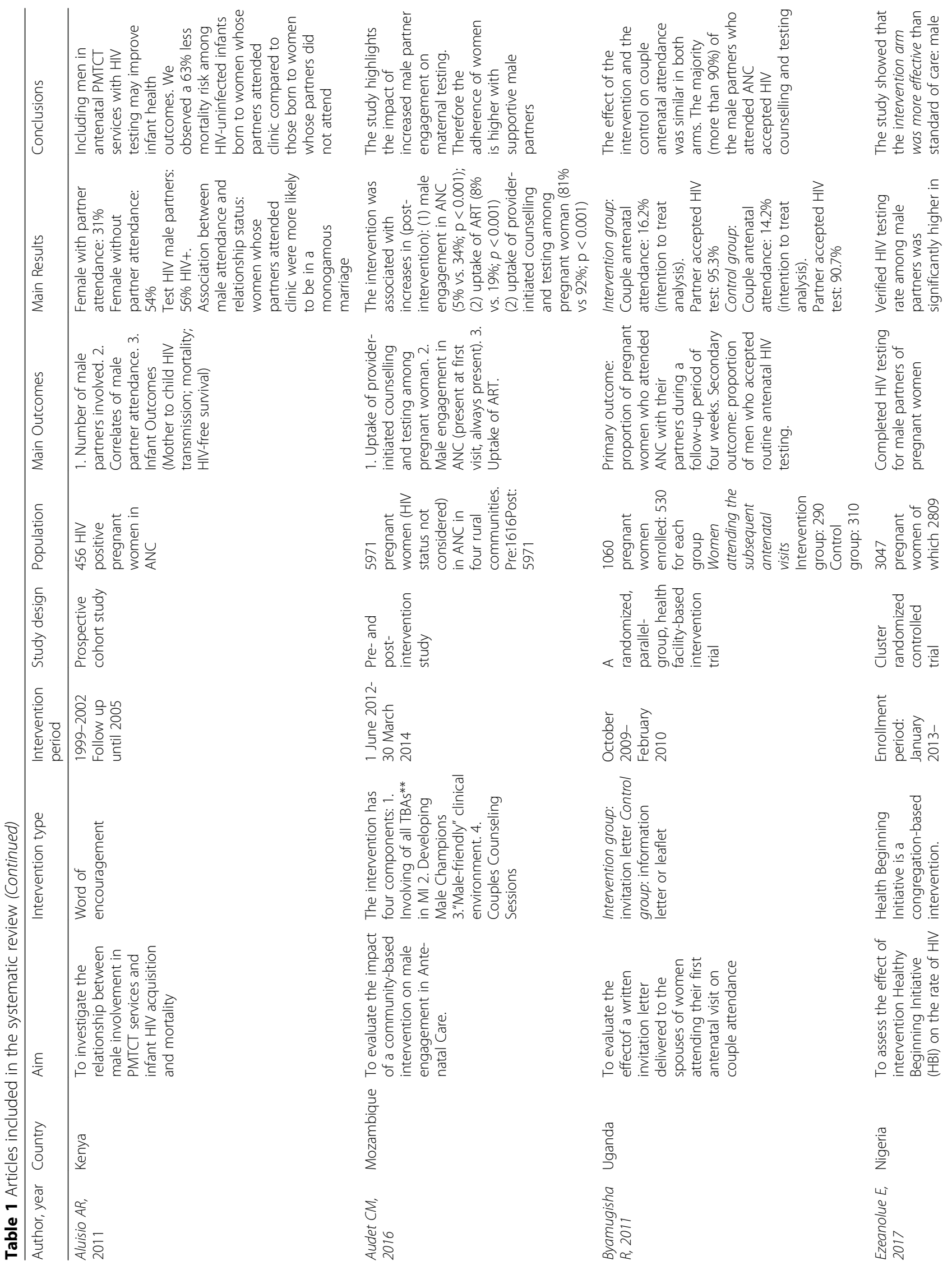




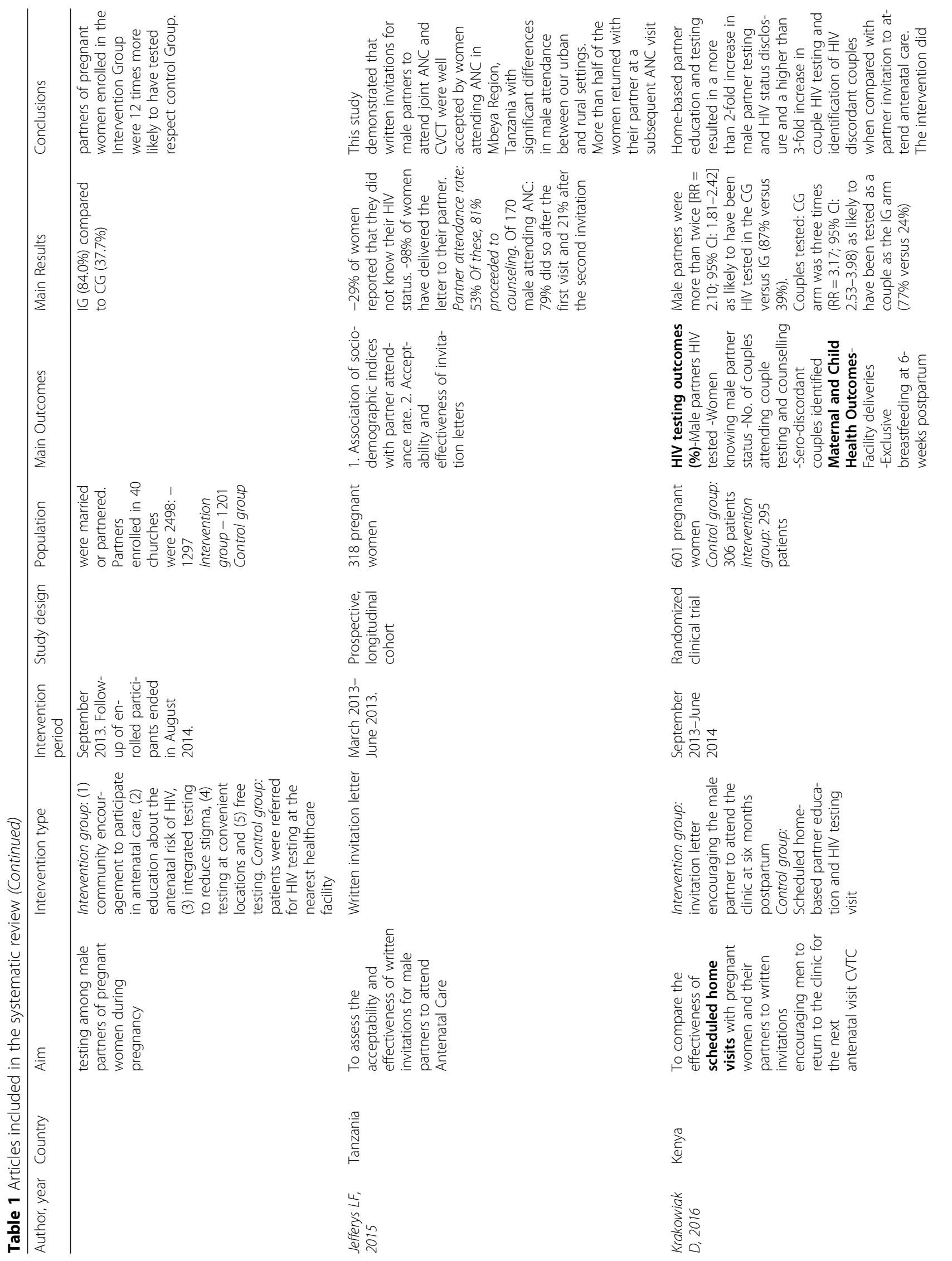




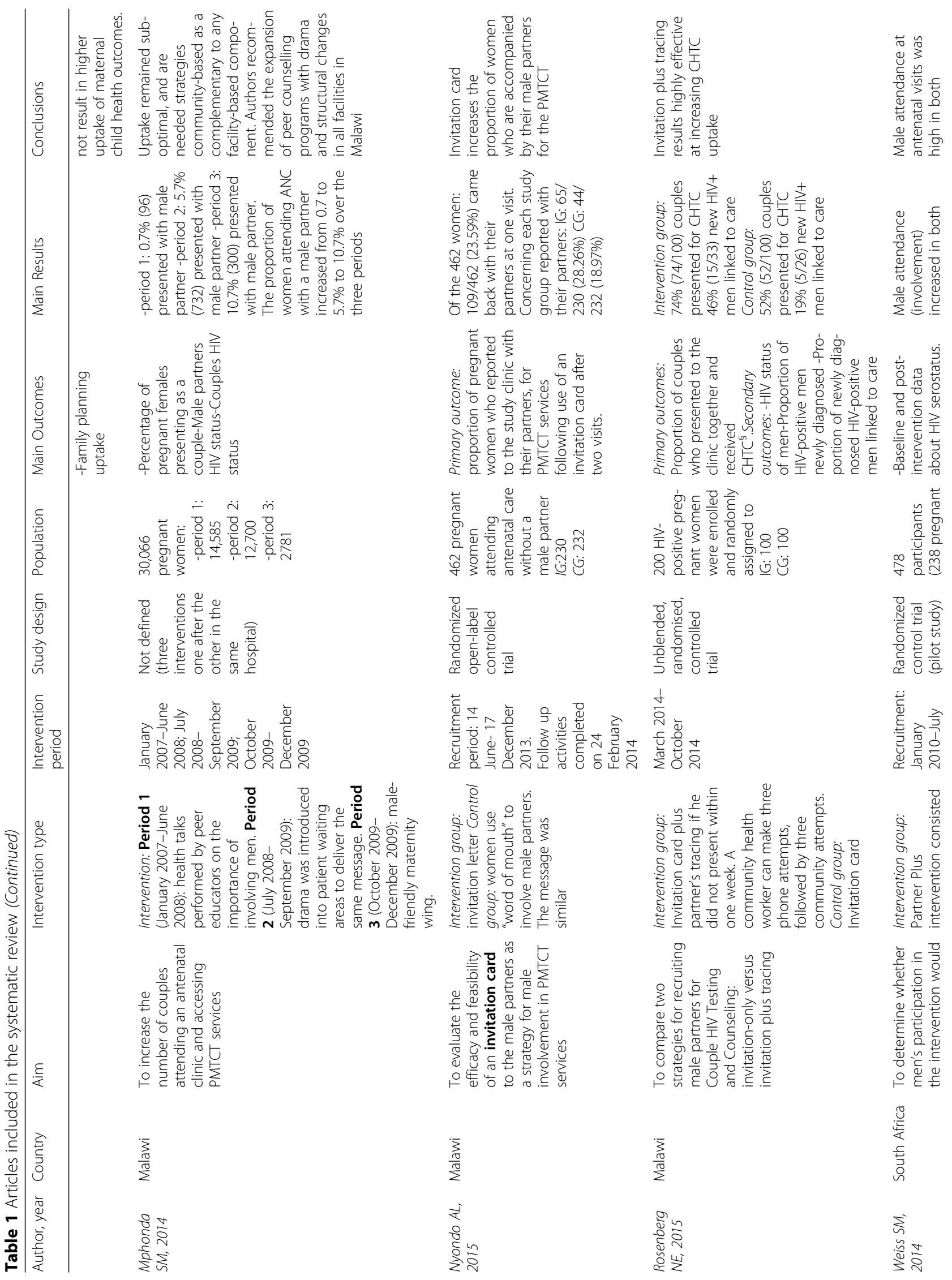




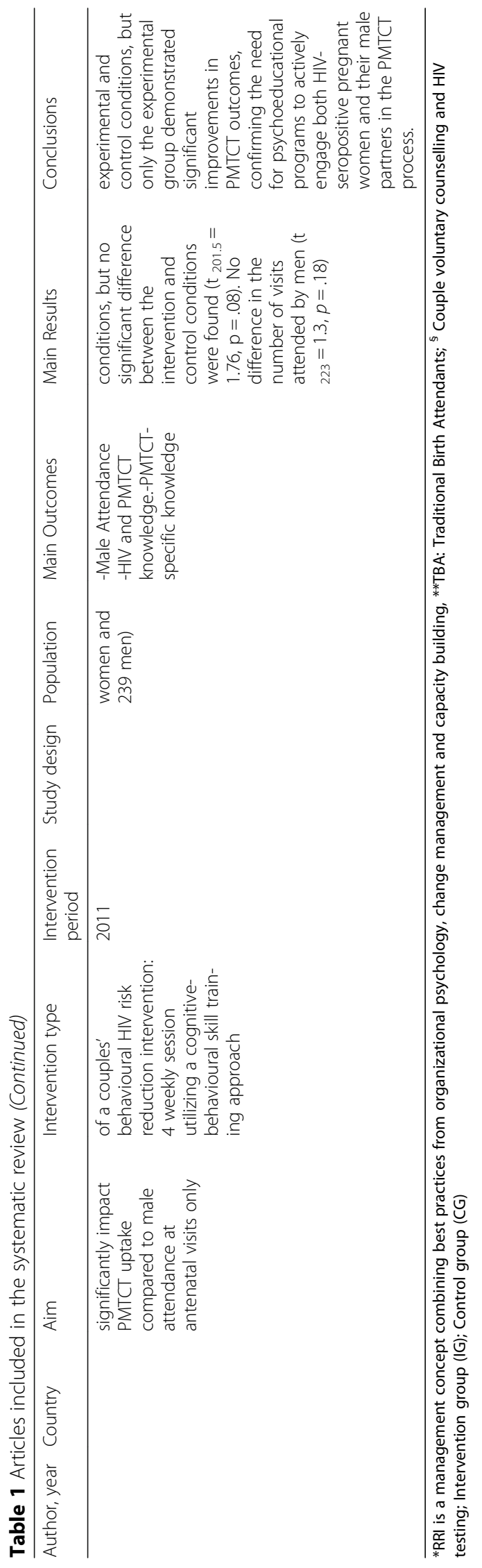


In all six studies men were encouraged to attend the antenatal care through invitation card or letter sent via their partners. We considered the invitation card or letter as the standard of care of each study described in this session.

Two studies evaluated the use of an invitation letter: in Aluisio et al. [29], among 830 enrolled women, 62.5\% $(519 / 830)$ agreed to involve males and 26.2\% (136/519) of partners attended ANC, while in the paper of Jefferys et al. [27] partner attendance rates reached 53.5\% (170/ 318) during the study period.

Four RCTs compared the invitation card to word of mouth [30], information letter [24], home visits [31] and invitation card plus partner tracing [32]. Word of mouth seems less effective than SC. Among 462 randomized women, $28.26 \%(65 / 230)$ of the women came back with their partners in the standard of care group compared to $18.97 \%(44 / 232)$ in the word of mouth group. Therefore, women in the SC group were more likely to be accompanied by their male partners (intention to treat analysis RR: 1.49 (95\% CI:1.06-2.09); $p=0.02$; per protocol analysis RR: 1.43 , (1.03-1.97); $p=0.03)$ than women in the word of mouth group [30].

In the study performed by Byamugisha et al. [24], the use of the invitation letter is compared to a leaflet related to the healthcare services delivered in the antenatal clinic. The researchers found out similar effect in both group: $16.2 \%$ (86/530) of pregnant women attended ANC with their partners in the standard of care and $14.2 \%(75 / 530)$ in the leaflet group (unadjusted $\mathrm{OR}=1.2$; 95\% CI:0.8-1.6; intention to treat analysis).

Krakowiak et al. [31] enrolled 1101 pregnant women attending their first antenatal visit at Kisumu Country Hospital (Kenya). Women were randomly assigned to two groups: in first group, they received a scheduled home-based partner education including HIV testing (within 2 weeks of enrolment); in the second group, the women received an invitation card asking the asking partner to attend the clinic for HIV couples counselling and testing visit (6 months post-partum). Male were more than twice $[R R=2.10 ; 95 \% \mathrm{CI}: 1.81$ to 2.42$]$ as likely to have been HIV tested in the scheduled home visits [87\% (233/247)] as compared to standard of care [39\% (108/240)] at 6 months post-partum. In this research study, couples testing was proposed to couples. In the home visit group, couples were three times $(\mathrm{RR}=$ 3.17; 95\% CI: $2.53-3.98$ ) as likely to have been tested than the standard of care group (77\% versus $24 \%$, respectively).

The RTC conducted by Rosenberg et al. [32] compared the invitation plus tracing intervention (first arm) to the standard of care (second arm). The women received an invitation card and in the first arm the partners were traced if they did not come to the centre for couples HIV testing and counselling (CHTC). A community health worker outlined the male partners through phone calls and community encounters. In the standard of care group, only $52 \%(52 / 100)$ of couples presented for CHTC, while in the invitation plus tracing, $74 \%$ presented for CHTC (74/100).

\section{Word of encouragement intervention}

In the study of Aluisio et al. [6], women were encouraged to invite their partners for participation. The article examined the interrelation between male involvement and infant HIV acquisition and mortality through a prospective cohort study. The researchers used a strategy to raise partner awareness in women. Men were proposed Voluntary Counselling and Testing (VCT) and those who accepted were invited to come back after 1 week for the test's results and counselling. Among the enrolled HIV-infected pregnant women (456), $31 \%(140 / 456)$ of partners attended the antenatal clinic, 54\% (75/140) were tested, and 56\% (42/75) were HIV positive.

\section{Multiple integrated components}

Five papers included multiple integrated components. These interventions showed an effect on multiple levels of the health behaviour change model for HIV prevention and AIDS care. This socio-ecological model [33] presents all the factors influencing HIVrelated behaviour and considers the complex interaction between individual, relationship, community, and societal factors [34]. In the review process, we considered this model.

As described in Fig. 2, all studies focused on individual interventions and the institutional/health system level, only two focused on the community level, and two focused on the interpersonal/network level.

The studies were classified by dividing interventions between those who target men and offer health education $[28,35,36]$ and those who aim to train professional figures in the healthcare sector working with the MI target [26]. Akama et al. [22] described more complex multi-faceted interventions.

Among these five studies, two were RCT $[35,36]$, two were pre-post intervention design $[22,26]$ and one consisted of three interventions, one after the other in the same hospital [28].

In the pre-post intervention study, Audet et al. [26] designed four component interventions including involvement of Traditional Birth Assistance in MI, developing male champions figures, creating male friendly clinics and implementing couple sessions. Five thousand nine hundred seventy-one pregnant women were enrolled; during the period, rate of male accompaniment at the first or at any ANC appointment increased (respectively $5 \%$ vs. $34 \% p<0.001$ and 


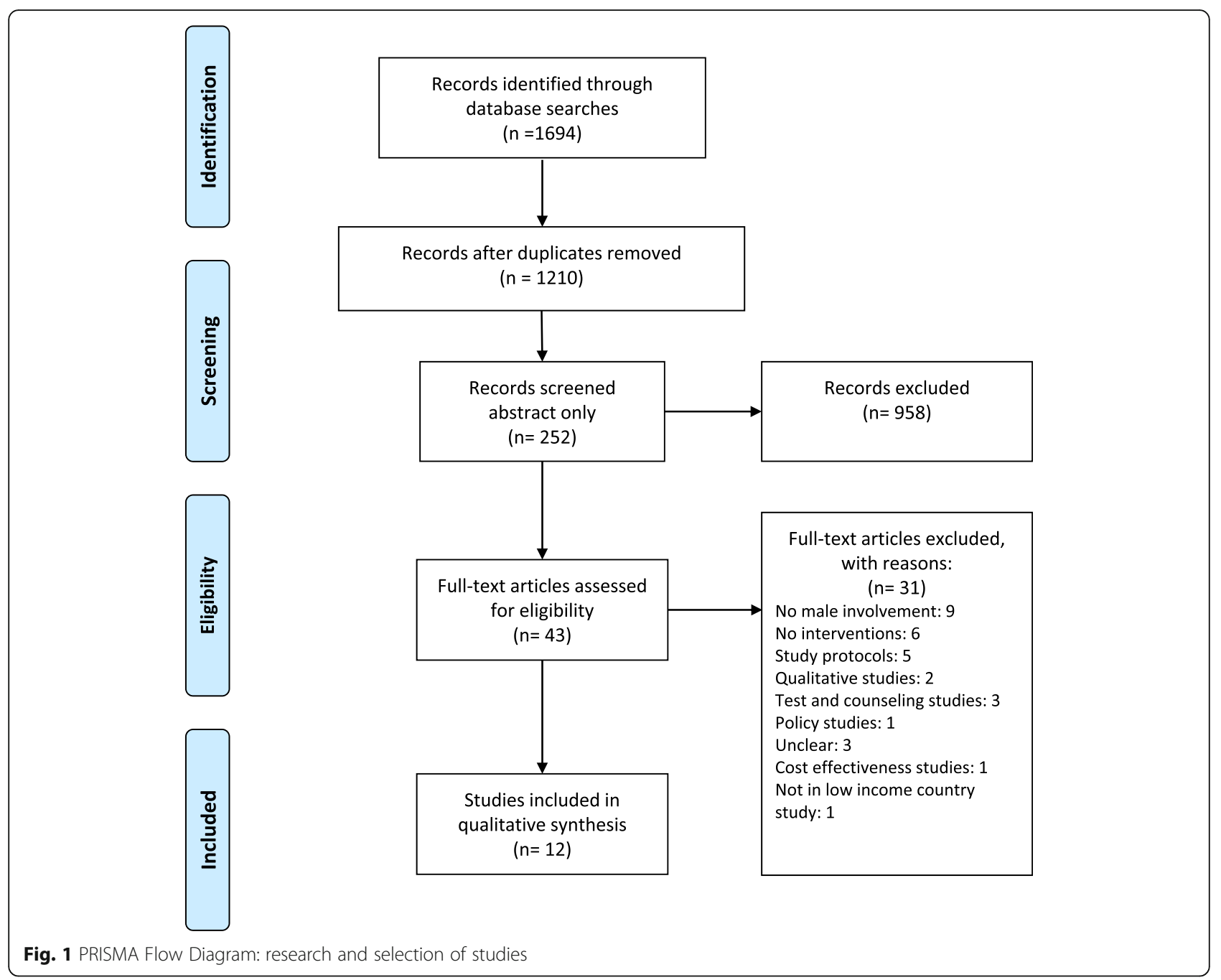

$10 \%$ vs $37 \% \mathrm{p}<0.001)$, and an increment in the rate of HIV testing for male partners during ANC was observed $(9 \%$ vs $34 \% ; \mathrm{p}<0.001)$. Women who were accompanied by partners to the ANC received more likely HIV testing (aOR: 5.98; 95\% CI: 4.50-7.94; $\mathrm{p}<$ 0.001), attended three ANC visits (aOR: 1.26; 95\% CI: $1.10-1.45 ; \mathrm{p}<0.001)$, and delivered in a health facility (aOR: 1.26; 95\% CI: $1.08-1.47 ; p=0.003$ ).

In the RCT conducted by Ezeanolue and colleagues [35], a sample of pregnant women attending church activities was analysed. The effectiveness of a congregation-based Healthy Beginning Initiative versus a clinic-based approach on the rates of HIV testing was investigated. The intervention provided men with 1) community support to participate in antenatal care; 2) education about HIV infection and antenatal risk; 3) free laboratory exams during a church-organized 'baby shower.' The intervention was intended to promote HIV testing of male partners, enhance tracking and strengthen linkage to the health service.

In this study, 40 churches in Nigeria were randomized, 3047 women and 2498 partners were enrolled during prayer sessions. The intervention arm was more effective than standard of care, in fact $84.0 \%(1089 / 1297)$ of males undertook HIV testing versus $37.7 \%(453 / 1201)\left(x^{2}=\right.$ $564.48, p<.001)$ in the standard of care. Male partners who received the interventions underwent HIV testing12 times more often compared to the standard of care $(\mathrm{aOR}=11.9 ; p<.01)$.

Mphonda et al. [28] introduced three interventions: one after the other in the same hospital from January 2007 to June 2008, from July 2008 to September 2009 and from October 2009 to December 2009. The interventions included health talks, drama in the patient's waiting-areas and an only-for-men clinic area. An increment from $0.7 \%(96 / 14585)$ to $5.7 \%(732 / 12700)$ to $10.7 \%(300 / 2781)$ was registered in the number of men 
Table 2 The outcomes related to men involvement

\begin{tabular}{|c|c|c|c|c|c|c|}
\hline & $\begin{array}{l}\text { Proportion of pregnant } \\
\text { women who attended ANC } \\
\text { with their partners }\end{array}$ & $\begin{array}{l}\text { Proportion of men who } \\
\text { accepted routine } \\
\text { antenatal HIV testing }\end{array}$ & $\begin{array}{l}\text { HIV status of } \\
\text { men/newly } \\
\text { diagnosed }\end{array}$ & $\begin{array}{l}\text { Proportion of newly } \\
\text { diagnosed HIV-positive } \\
\text { men linked to care }\end{array}$ & $\begin{array}{l}\text { HIV testing } \\
\text { outcomes* }\end{array}$ & $\begin{array}{l}\text { Maternal and } \\
\text { Child Health } \\
\text { Outcomes** }^{* *}\end{array}$ \\
\hline \multicolumn{7}{|c|}{ Single Intervention } \\
\hline \multicolumn{7}{|c|}{$\begin{array}{l}\text { Interventions based } \\
\text { on Invitation letter }\end{array}$} \\
\hline $\begin{array}{l}\text { Aluisio et al. } \\
\text { [29] }\end{array}$ & $x$ & & & & & \\
\hline $\begin{array}{l}\text { Byamugisha } \\
\text { et al. [24] }\end{array}$ & $x$ & $x$ & & & & \\
\hline $\begin{array}{l}\text { Krakowiak } \\
\text { et al. [31] }\end{array}$ & & & $x$ & & $x$ & $x$ \\
\hline $\begin{array}{l}\text { Jefferys } \\
\text { et al. [27] }\end{array}$ & $x$ & & & & & \\
\hline $\begin{array}{l}\text { Nyondo } \\
\text { et al. [30] }\end{array}$ & $x$ & & & & & \\
\hline $\begin{array}{l}\text { Rosenberg } \\
\text { et al. [32] }\end{array}$ & $x$ & & $x$ & $x$ & & \\
\hline \multicolumn{7}{|c|}{$\begin{array}{l}\text { Intervention based } \\
\text { on Word of encouragement }\end{array}$} \\
\hline $\begin{array}{l}\text { Aluisio et al. } \\
\text { [6] }\end{array}$ & & $x$ & $x$ & $x$ & & $x$ \\
\hline \multicolumn{7}{|c|}{$\begin{array}{l}\text { Multiple integrated } \\
\text { components }\end{array}$} \\
\hline $\begin{array}{l}\text { Akama et al. } \\
{[22]}\end{array}$ & $x$ & $x$ & & & $x$ & $x$ \\
\hline $\begin{array}{l}\text { Audet et al. } \\
{[26]}\end{array}$ & $x$ & & & & $x$ & \\
\hline $\begin{array}{l}\text { Ezeanolue } \\
\text { et al. [35] }\end{array}$ & & $x$ & & & & \\
\hline $\begin{array}{l}\text { Mphonda } \\
\text { et al. [28] }\end{array}$ & $x$ & & & & $x$ & \\
\hline $\begin{array}{l}\text { Weiss et al. } \\
{[36]}\end{array}$ & $x$ & & & & $x$ & \\
\hline
\end{tabular}

* Male HIV tested, Female knows male status, tested as couple Serodiscordant couples identified

** In Krakowian et al. [31] "Facility delivery, Exclusive breastfeeding at 6-weeks postpartum, Exclusive breastfeeding at 6-months postpartum then family-planning hormonal, intrauterine device, or sterilization use at six weeks postpartum and 6 months postpartum". In Aluisio et al. [6] and Akama et al. [22] child health outcomes refer to mortality and HIV free survival and EID uptake infants (0-8 months), respectively

accompanying their spouse to ANC over the three periods.

The RCT of Weiss et al. [36] compared an intervention to reduce behavioural HIV risk in couples combined with a medication adherence intervention to standard of care. This intervention was based on a cognitive-behavioural approach through 4 weekly sessions. An increment in male attendance was observed under both conditions, an increment in knowledge of HIV and PMTCT topics was observed only in the group involved in the intervention. Looking at the number of visits attended by women, no significant difference was observed between the two groups: $5.7 \pm 1.5$ for the intervention group versus versus $2.2 \pm 1.8\left(\mathrm{t}_{201.5}=1.76, p=.08\right)$ for control group. The same in the male attendance to visits $\left(\mathrm{t}_{223}=1.3, p=.18\right)$.
Not even differences were noted according to provenience (rural vs non-rural) and occupational status (employed vs unemployed).

Akama et al. [22] described a package of interventions, that showed effect at community, health facility and individual levels: community mobilization, health education in the waiting areas, invitation letters, peer educators and mentor mothers equipped with mobile phones, text reminders and phone calls to male partners, leveraged existing community units for mobilization, fast tracked clinic visits and abbreviated medical check-ups.

The study involved 116 ANC in Western Kenya, assessing male involvement pre and post- intervention. An increment from $7.4 \%$ to $54.2 \%$ ( $R D=0.47$, CI $0.45-0.48$ ) was observed in the number of men escorting their partners to the clinic 
and receiving counselling at baseline and during intervention respectively. A further reduction to $43.4 \%(\mathrm{RD}=0.36$, CI 0.35-0.37) was observed in the post-intervention period.

In Table 2, we describe the outcomes used in all the studies included in the systematic review.

\section{Discussion}

In the present study, we conducted a systematic review of all the interventions aimed to increase the involvement of male partners in antenatal clinics. The characteristics of the interventions did not allow us to perform a meta-analysis, so we narratively described the interventions. We were interested in the effectiveness of male involvement interventions in term of attendance (as the proportion of men escorting their female pregnant partners to visits to ANC visits) and, where not present, male HIV testing. We highlighted only these outcomes in the results, although other outcomes were evaluated in the included studies. During the review process, we screened 1694 studies, and we included 12 papers.

The studies were conducted in 7 different SubSaharan countries, and population characteristics were not comparable, but the interventions including comparator arms (randomized controlled trial) or pre-post intervention studies seemed effective, excluding the couple behavioural HIV risk reduction intervention where male attendance increased in both arms [36].

From the recent literature research, three systematic reviews emerged which presented different strategies to involve men in maternal and childcare. The systematic review performed by Tokhi et al. [37] aimed to measure the effect of interventions to increase male involvement during pregnancy and first year of life in order to improve maternal and newborn health. The included studies (13) showed that the engagement of men in maternal and newborn health positively impacted on relationship dynamics.

The review of Takah et al. [38] including 17 studies (4 randomised trials and 13 observational studies) based in SSA, aimed to identify the strategies to improve men involvement in PMTCT programs and the consequent effect on adherence to ART in positive pregnant women. Takah et al. included also studies not clearly designed to.

The meta-analysis showed that community interventions were more effective than invitation letter in engaging men and adherence in PMTCT. The invitation letter did not demonstrate an effect.

The systematic review performed by Hensen et al. [39], focused on the involvement of men in HTC (HIV Test and Counseling) services in SSA and included 15 papers. Hensen et al. identified several number of interventions effective in increasing HTC services uptake by men, even when general population was targeted.

Furthermore, community-based programmes showed to be effective in increasing HTC access at population level.

These reviews represent an essential state of the art, but our review is focused on studies referring only to interventions or strategies that explicitly promote male partners in PMTCT, even if the final outcomes of the interventions is women's health.

Among the single interventions, the randomized controlled trial comparing the invitation card strategy to home visit was more effective for delivery of couples' HIV testing at home than the others. This intervention seemed more promising than word of mouth, information letter and the invitation plus tracing strategy. The partners' attendance rate was lower in SC than in the intervention arm: leaflet (14.2\% vs $16.2 \%)$, home visit (39\% vs $87 \%)$ and invitation card plus partner tracing (52\% vs $74 \%)$. Home visit strategies seemed the most effective [31].

The multi-component intervention showed higher effectiveness in terms of male accompaniment at the first ANC than the single interventions. These studies would likely to produce a change mainly at the individual, Institutional/health system level, and slightly at the interpersonal/network, community and structural levels.

Although male involvement increased in some studies [22, 26, 35], Akama et al. [22] and Audet et al. [26] assessed effective interventions in order to increase the number of men escorting their female partners at ANC visit (pre-intervention $7.4 \%$ - post-intervention $43.4 \%$; pre-intervention $5 \%$ - post-intervention $34 \%$, respectively) and Ezeanolue et al. [35] evaluated the percentage of men tested for HIV (intervention $84 \%$ vs standard of care $38 \%)$.

As shown in Fig. 2, Akama et al. and Ezeanolue et al. $[22,35]$ studies tried to assess the impact of the interventions in multiple levels of the Socio-ecological model [33] compared to other studies. The modern health promotion theory suggests multifaceted intervention target obstacles and facilitators are comparatively more effective [32].

Regarding outcomes assessed in the studies, many of the interventions evaluated the number of male partners escorting their female partners to ANC visit and accepting to be tested for HIV.

The number of studies identifying $\mathrm{MI}$ as a necessity was very high, while the number of studies able to identify the most effective interventions or strategies was somewhat limited. From this, we deduce 


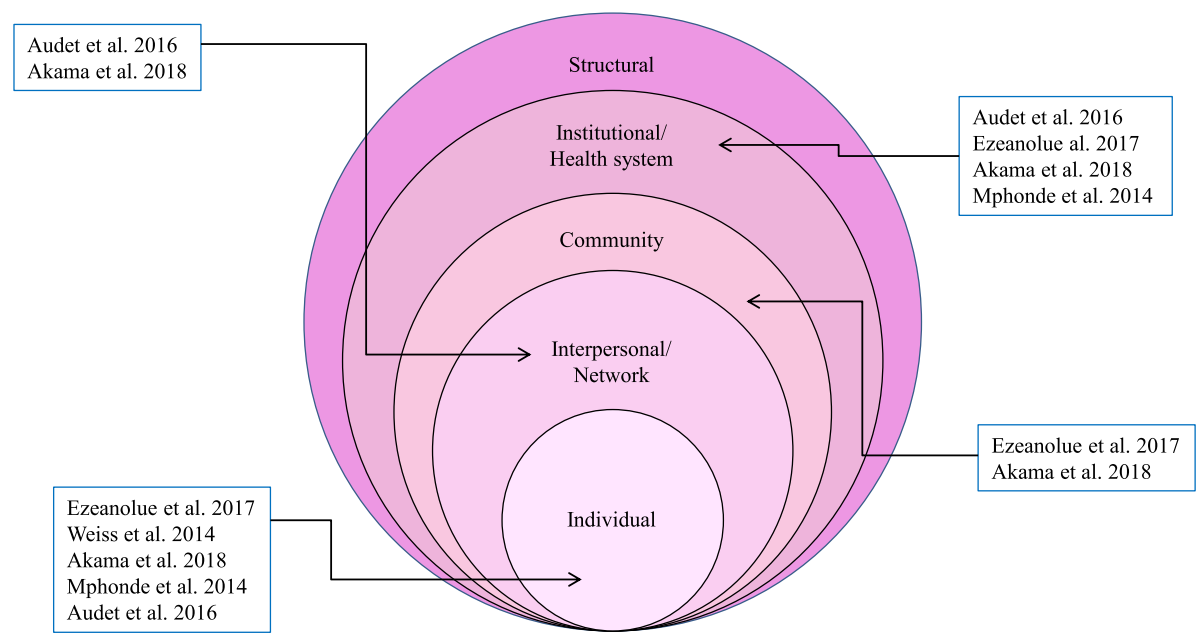

Fig. 2 Effect of multiple integrated component interventions on Socio-Social ecological model adapted by Kaufman et al. 2004

the need to carry out more studies in this area, and to define in a more precise way standard indicators to measure MI.

\section{Limitations of the study}

The search was comprehensive because the primary databases were reviewed. Two reviewers conducted independent search and screening of studies to reduce bias. Our systematic review has several limitations. Due to the resources available, we did not include a search for papers published in the grey literature. Moreover, we did undertake a search in languages other than English, and we did not include papers written in other languages as French, Spanish, Portuguese and Dutch.

Therefore, during our research, we realized that some studies are underway because study protocols have been published, but there are not yet published results (Trial registration number: ISRCTN18421340 and NCT02085356).

There are also limitations relating to our selection criteria. We decided to include only papers where the research was to improve male partner involvement, although we found studies where the objective was not to evaluate male involvement, but MI was reported together with other indicators.

The included studies were heterogeneous since they showed variability in the studied population, interventions, location and social context (country, urban or rural area), measured outcomes and study design.

\section{Conclusion}

A low number of studies aimed to improve male involvement was found in our search. The need to define clearer indicators for measuring male involvement is very apparent. There is also the need for development of more studies that have lower heterogeneity in regard to design, outcomes and geographic location. The review highlights the importance of male involvement in HIV cascade for pregnant women in countries with a significant HIV incidence. HIV counseling and testing is fundamental in the care process but is also very important for the continuum of the care after pregnancy both for women and their partners. The efficacy and effectiveness of implemented interventions need to be assessed over the long term.

\section{Supplementary information}

Supplementary information accompanies this paper at https://doi.org/10. 1186/s12913-019-4689-6.

Additional file 1: Table S1. Search terms. List of the electronic search strategies. Table S2: PRISMA 2009 Checklist PRISMA checklist items.

\section{Abbreviations}

ANC: Antenatal Clinic; aOR: Adjusted Odd Ratio; ART: Antiretroviral therapy; CG: Control group; CHTC: Couples HIV testing and counselling;

Cl: Confidence Interval; HTC: HIV Test \& Counseling; IG: Intervention group; MI: Male involvement; MTCT: Mother-to-Child Transmission; OR: Odd Ratio; PMTC: Prevention of Mother-to-Child Transmission; PPTCT: Prevention of Parent to Child Transmission; PRISMA: Preferred Reporting Items for Systematic Reviews and Meta-Analyses; RCTs: Randomized Controlled Trials; RD: Risk Difference; RR: Risk Relative; SC: Standard of Care; SSA: Sub-Saharan Africa; VCT: Voluntary Counselling and Testing

\section{Acknowledgements} Not applicable.

Available of data and material Not applicable. 


\section{Authors' contributions}

IT carried out the systematic review, conceived the study, and participated in its design, coordination and drafted the manuscript. IP participated in the design of the review, data collection process and helped to draft the manuscript. FC and SO participated in the interpretation of the results and helped to draft the manuscript. LP and GT participated in the coordination of the study. All authors read, reviewed and approved the final manuscript.

\section{Funding}

Not applicable.

\section{Ethics approval and consent to participate}

Not applicable.

\section{Consent for publication}

Not applicable.

\section{Competing interests}

No disclosed financial or nonfinancial competing interests by all authors.

\section{Author details}

'Institute of Management, Scuola Superiore Sant'Anna, Piazza Martiri della Libertà, 33, 56127 Pisa, Italy. ${ }^{2}$ Department of Biomedicine and Prevention, University of Tor Vergata, Rome, Italy. International University of Health and Medical Science, UniCamillus, Rome, Italy.

Received: 23 April 2019 Accepted: 28 October 2019

Published online: 09 December 2019

\section{References}

1. World Health Organization. Guidance on couples HIV testing and counselling including antiretroviral therapy for treatment and prevention in serodiscordant couples: recommendations for a public health approach. 2012.

2. World Health Organization. WHO recommendations on health promotion interventions for maternal and newborn health. 2015.

3. Msuya SE, Mbizvo EM, Hussain A, Uriyo J, Sam NE, Stray-Pedersen B. Low male partner participation in antenatal HIV counselling and testing in northern Tanzania: implications for preventive programs. AIDS Care. 2008 Jul;20(6):700-9.

4. Tenthani L, Haas AD, Tweya H, Jahn A, van Oosterhout JJ, Chimbwandira F, et al. Retention in care under universal antiretroviral therapy for HIV-infected pregnant and breastfeeding women ('Option B+') in Malawi. AIDS. 2014; 28(4):589-98.

5. Nyondo AL, Chimwaza AF, Muula AS. Stakeholders' perceptions on factors influencing male involvement in prevention of mother to child transmission of HIV services in Blantyre. Malawi BMC Public Health. 2014:14:691.

6. Aluisio A, Richardson BA, Bosire R, John-Stewart G, Mbori-Ngacha D, Farquhar C. Male antenatal attendance and HIV testing are associated with decreased infant HIV infection and increased HIV-free survival. J Acquir Immune Defic Syndr. 2011;56(1):76-82.

7. Engebretsen IMS, Moland KM, Nankunda J, Karamagi CA, Tylleskär T, Tumwine JK. Gendered perceptions on infant feeding in eastern Uganda: continued need for exclusive breastfeeding support. Int Breastfeed J. 2010;5.

8. Farquhar C, Kiarie JN, Richardson BA, Kabura MN, John FN, Nduati RW, et al. Antenatal couple counseling increases uptake of interventions to prevent HIV-1 transmission. J Acquir Immune Defic Syndr. 2004;37(5):1620-6.

9. World Health Organization. Male involvement in the prevention of motherto-child transmission of HIV. 2012.

10. Gourlay A, Birdthistle I, Mburu G, lorpenda K, Wringe A. Barriers and facilitating factors to the uptake of antiretroviral drugs for prevention of mother-to-child transmission of HIV in sub-Saharan Africa: a systematic review. J Int AIDS Soc. 2013 Jul;16:18588.

11. Cuco RMM, Munguambe K, Osman NB, Degomme O, Temmerman M, Sidat MM. Male partners ' involvement in prevention of mother-to-child HIV transmission in sub-Saharan Africa. Syst Rev. 2016;0376.

12. Morfaw F, Mbuagbaw L, Thabane L, Rodrigues C, Wunderlich A-P, Nana P, et al. Male involvement in prevention programs of mother to child transmission of HIV: a systematic review to identify barriers and facilitators. Syst Rev. 2013;2:5.
13. Unaids HIV. Addressing a blind spot in the response to HIV — reaching out to men and boys; 2017.

14. Baker P, Shand T. Men's health: time for a new approach to policy and practice? J Glob Health. 2017;7(1):010306.

15. Dovel K, Yeatman S, van Oosterhout JJ, Chan A, Mantengeni A, Landes M, et al. Trends in ART initiation among men and non-pregnant/nonbreastfeeding women before and after option B+ in southern Malawi. PLoS One. 2016;11(12):e0165025.

16. Ostlin P, Eckermann E, Mishra US, Nkowane M, Wallstam E. Gender and health promotion: a multisectoral policy approach. Health Promot Int. 2006; 21(Suppl 1):25-35.

17. Nyondo AL, Chimwaza AF, Muula AS. Exploring the relevance of male involvement in the prevention of mother to child transmission of HIV services in Blantyre. Malawi BMC Int Health Hum Rights. 2014;14:30.

18. Mkandawire $\mathrm{E}$, Hendriks SL. A qualitative analysis of men's involvement in maternal and child health as a policy intervention in rural Central Malawi. BMC Pregnancy Childbirth. 2018;18(1):1-12.

19. Sharma AL, Singh TR, Devi KR, Singh LS. Molecular epidemiology of HIV-1 among the HIV infected people of Manipur, northeastern India: emergence of unique recombinant forms. J Med Virol. 2017;89(6):989-99.

20. Munn Z, Peters MDJ, Stern C, Tufanaru C, McArthur A, Aromataris E. Systematic review or scoping review? Guidance for authors when choosing between a systematic or scoping review approach. BMC Med Res Methodol. 2018;18(1):1-7.

21. Falagas ME, Pitsouni El, Malietzis GA, Pappas G. Comparison of PubMed, Scopus, web of science, and Google scholar: strengths and weaknesses. FASEB J. 2007:22(2):338-42.

22. Akama E, Mburu M, Mutegi E, Nyanaro G, Otieno JP, Ndolo S, et al. Impact of a rapid results initiative approach on improving male partner involvement in prevention of mother to child transmission of HIV in Western Kenya. AIDS Behav. 2018;22(9):2956-65.

23. Aliyu MH, Blevins M, Audet CM, Kalish M, Gebi UI, Onwujekwe O, et al. Integrated prevention of mother-to-child HIV transmission services, antiretroviral therapy initiation, and maternal and infant retention in care in rural north-Central Nigeria: a cluster-randomised controlled trial. Lancet HIV. 2016;3(5):e202-11.

24. Byamugisha R, Astrom AN, Ndeezi G, Karamagi CAS, Tylleskar T, Tumwine JK. Male partner antenatal attendance and HIV testing in eastern Uganda: a randomized facility-based intervention trial. J Int AIDS Soc. 2011;14:43.

25. Grimes DA, Schulz KF. Epidemiology series an overview of clinical research : the lay of the land. Epidemiol Ser. 2002;359:57-61.

26. Audet CM, Blevins M, Chire YM, Aliyu MH, Vaz LME, Antonio E, et al. Engagement of men in antenatal care services: increased HIV testing and treatment uptake in a community participatory action program in Mozambique. AIDS Behav. 2016;20(9):2090-100.

27. Jefferys $L F, N$ Nhimbi $P$, Mbezi $P$, Sewangi J, Theuring S. Official invitation letters to promote male partner attendance and couple voluntary HIV counselling and testing in antenatal care: an implementation study in Mbeya region. Tanzania Reprod Health. 2015;12(1):95.

28. Mphonda SM, Rosenberg NE, Kamanga E, Mofolo I, Mwale G, Boa E, et al. Assessment of peer-based and structural strategies for increasing male participation in an antenatal setting in Lilongwe. Malawi Afr J Reprod Health. 2014:18(2):97-104.

29. Aluisio AR, Bosire R, Bourke B, Gatuguta A, Kiarie JN, Nduati R, et al. Male partner participation in antenatal clinic services is associated with improved HIV-free survival among infants in Nairobi, Kenya: a prospective cohort study. J Acquir Immune Defic Syndr. 2016;73(2):169-76.

30. Nyondo AL, Choko AT, Chimwaza AF, Muula AS. Invitation cards during pregnancy enhance male partner involvement in prevention of mother to child transmission (PMTCT) of human immunodeficiency virus (HIV) in Blantyre, Malawi: a randomized controlled open label trial. PLoS One. 2015;10(3):1-13.

31. Krakowiak D, Kinuthia J, Osoti AO, Asila V, Gone MA, Mark J, et al. Homebased HIV testing among pregnant couples increases partner testing and identification of Serodiscordant partnerships. J Acquir Immune Defic Syndr. 2016;72(Suppl 2):S167-73.

32. Rosenberg NE, Mtande TK, Saidi F, Stanley C, Jere E, Paile L, et al. Recruiting male partners for couple HIV testing and counselling in Malawi's option B+ programme: an unblinded randomised controlled trial. Lancet HIV. 2015; 2(11):e483-91.

33. Armstrong R, Waters E, Jackson N, Ol iver S, Popay J, Shepherd J, Petticrew M AL, Bai I ie R, Brunton G, Hawe P, Kristjansson E, Naccarel la L, Norris S, 
Pienaar E RH, Rogers W, Sowden A TH. Guidelines for Systematic Reviews in Health Promotion and Public Health Taskforce. Version 2. Melbourne University: October 2007; 2007.

34. Kaufman MR, Cornish F, Zimmerman RS, Johnson BT. Health Behavior Change Models for HIV Prevention and AIDS Care : Practical Recommendations for a Multi-Level Approach 2014;66:250-258.

35. Ezeanolue EE, Obiefune MC, Yang W, Ezeanolue CO, Pharr J, Osuji A, et al. What do you need to get male Partners of Pregnant Women Tested for HIV in resource limited settings? The baby shower cluster randomized trial. AIDS Behav. 2017 Feb;21 (2):587-96.

36. Weiss SM, Karl P, Olga VL, Shikwane ME, Ryan C, Jones DL. Improving PMTCT uptake in rural South Africa. J Int Assoc Provid AIDS Care. 2014;13(3):269-76.

37. Tokhi M, Comrie-Thomson L, Davis J, Portela A, Chersich M, Luchters S. Involving men to improve maternal and newborn health: a systematic review of the effectiveness of interventions. PLoS One. 2018:13(1):1-16.

38. Takah NF, Kennedy ITR, Johnman C. The impact of approaches in improving male partner involvement in the prevention of mother-to-child transmission of HIV on the uptake of maternal antiretroviral therapy among HIVseropositive pregnant women in sub-Saharan Africa: a systematic review and meta-analysis. BMJ Open. 2017 Nov 25;7(11):e018207.

39. Hensen B, Taoka S, Lewis JJ, Weiss HA, Hargreaves J. Systematic review of strategies to increase men's HIV-testing in sub-Saharan Africa. Aids. 2014; 28(14):2133-45.

\section{Publisher's Note}

Springer Nature remains neutral with regard to jurisdictional claims in published maps and institutional affiliations.

Ready to submit your research? Choose BMC and benefit from:

- fast, convenient online submission

- thorough peer review by experienced researchers in your field

- rapid publication on acceptance

- support for research data, including large and complex data types

- gold Open Access which fosters wider collaboration and increased citations

- maximum visibility for your research: over $100 \mathrm{M}$ website views per year

At $\mathrm{BMC}$, research is always in progress.

Learn more biomedcentral.com/submissions 